\title{
Paediatric neurosurgical implications of a ribosomopathy: illustrative case and literature review
}

\author{
Suzanne Murphy ${ }^{1}$ (D) $\cdot$ Gabriella Grima $^{2} \cdot$ Kshitij Mankad $^{3} \cdot$ Kristian Aquilina $^{2}$
}

Received: 27 January 2021 / Accepted: 5 May 2021 / Published online: 21 May 2021

(C) The Author(s) 2021

\begin{abstract}
Ribosomopathies are rare, recently defined entities. One of these, Labrune syndrome, is recognisable radiologically by its distinctive triad of leukoencephalopathy, intracranial calcifications and cysts (LCC). These cysts may have neurosurgical implications at different ages because of their progressive expansion and local mass effect. The aetiology of LCC is related to a widespread cerebral microangiopathy and is due to a genetic mutation in SNORD118, responsible for stabilisation of the large ribosomal subunit during assembly.
\end{abstract}

Keywords Ribosomopathy $\cdot$ Labrune syndrome $\cdot$ SNORD118 $\cdot$ LCC $\cdot$ Hydrocephalus

\section{Introduction}

Ribosomopathies are a diverse group of tissue-specific diseases caused by reduced expression, or mutation, of factors necessary for the synthesis of ribosomes [1]. These include, among others, Treacher Collins syndrome, Diamond Blackfan and some types of congenital cirrhosis. Leukoencephalopathy with cerebral calcifications and cysts (LCC), also known as Labrune syndrome, was first described in three children in 1996, who presented with cognitive deterioration and seizures beginning in early infancy $[2,3]$. Several cases have now been reported in adults and children [4-30].

The triad of LCC is evident on imaging. The primary cause is an isolated cerebrovascular microangiopathy, inherited in an autosomal recessive manner, and related to a mutation in the SNORD118 gene that is essential for maturation of the $60 \mathrm{~S}$ subunit of the ribosome. The presence of multiple cysts, often deep within the brain in eloquent locations, and their tendency to recur, represents a significant neurosurgical challenge. The

Suzanne Murphy

Suzannemmurphy@rcsi.com

School of Medicine, Royal College of Surgeons, Dublin, Ireland

2 Department of Neurosurgery, Great Ormond Street Hospital NHS Foundation Trust, London, UK

3 Department of Neuroradiology, Great Ormond Street Hospital NHS Foundation Trust, London, UK objective of this study is to illustrate a new paediatric case of LCC and review the neurosurgical strategies that have been used to manage this rare and difficult condition.

\section{Case illustration}

A 4-year-old girl initially presented to another institution with a 1-week history of headache and vomiting. A CT scan of the brain showed bilateral thalamic cysts with calcifications. In order to exclude a thalamic tumour, she underwent stereotactic biopsy with drainage of the large left-sided cyst at the same time. She subsequently developed symptomatic hydrocephalus, and a right frontal VP shunt was inserted (Fig. 1A). The biopsy showed no evidence of tumour, but demonstrated areas of Rosenthal fibre deposition, calcification and demyelination. These findings on histology, together with the absence of tumour and the typical triad on imaging, confirmed the diagnosis of LCC.

She was referred to our institution 6 months later, with worsening headache, ataxia and bilateral coarse hand tremor. There was no limb weakness or visual disturbance. Imaging showed progressive enlargement of the right thalamic cyst, with mass effect on the midbrain and pons (Fig. 1B). Further drainage of the cyst was performed. A catheter and Ommaya reservoir were inserted under image guidance into the cyst and $60 \mathrm{ml}$ of xanthochromic fluid was aspirated (Fig. 1). No cells or organisms were identified in the fluid. As an MRI scan would have required an additional general anaesthetic, a post-operative CT 
Fig. 1 Computed tomography scans, axial (A, B), coronal (C), and sagittal (D), to demonstrate the triad of calcification (single arrows), thalamic cysts on the left $(\mathrm{L})$ and right $(\mathrm{R})$, and leukoencephalopathy $(*)$ in the patient illustrated. The arrowhead in (A) and (D) denotes the ventricular catheter of the right ventriculoperitoneal shunt. The double arrow in (D) denotes the catheter directed to the now drained right thalamic cyst $(\mathrm{R})$; this was attached to an Ommaya reservoir to allow repeated dra
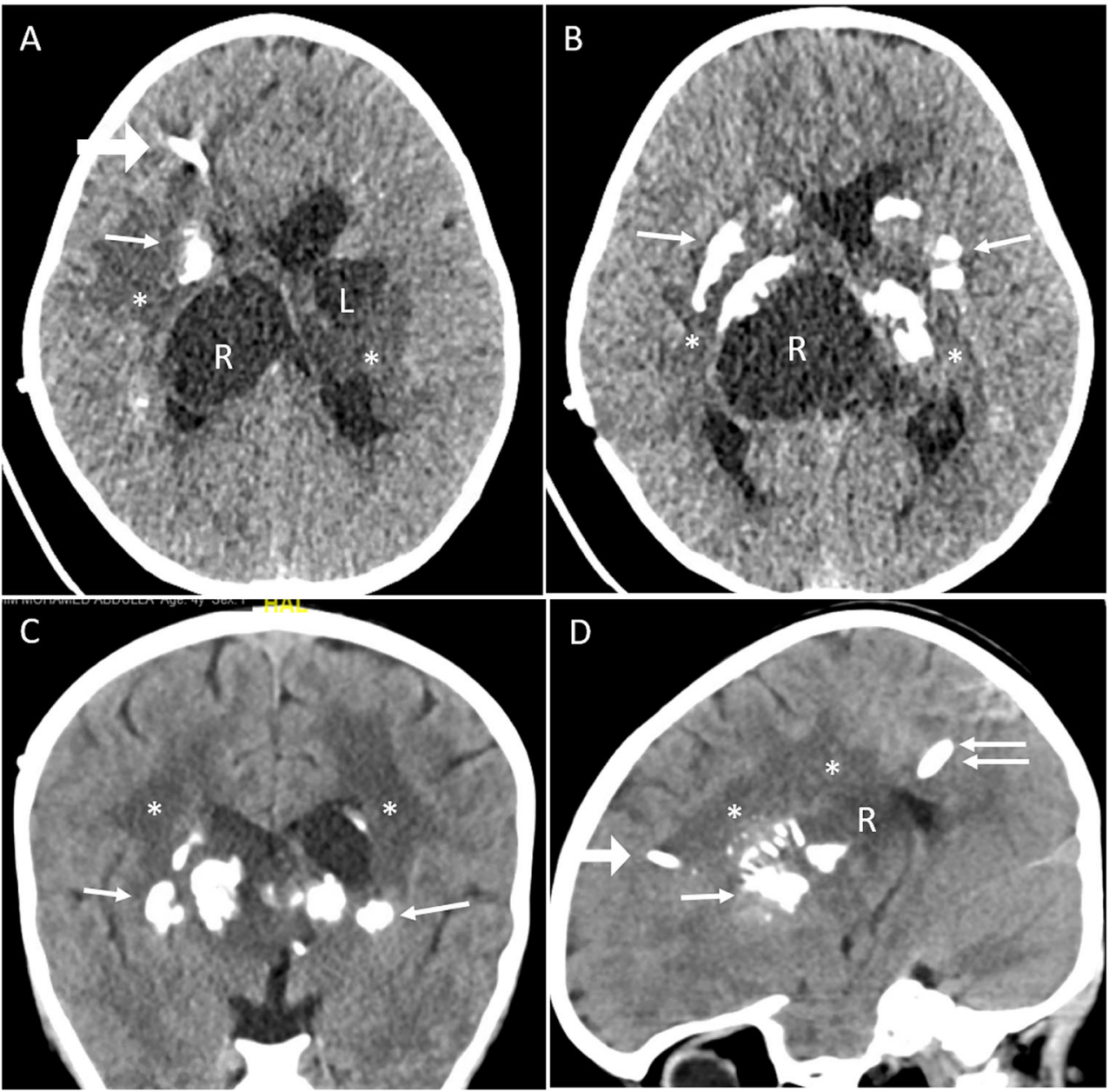

scan was carried out which demonstrated satisfactory drainage of the large right thalamic cyst (Fig. $1 \mathrm{C}$ and D). The child then returned to her home country. No further aspirations were necessary over a 1-year follow-up period.

\section{Discussion}

LCC is a rare progressive neurological disorder that can present at any age. We identified 39 cases reported in the last ten years (Table 1). Many adult patients reported symptoms from childhood $[8,9,12,20,26]$. LCC is clinically defined by the radiological triad, with development of asymmetric cysts, usually involving the thalami, basal ganglia, dentate nuclei and deep white matter, as well as diffuse hemispheric leukoencephalopathy and dystrophic calcification. Cerebral atrophy is absent. The primary change is the presence of microangiopathy in the brain, with ectasia of small cerebral blood vessels. There is deposition of Rosenthal fibres, with demyelination and calcification. Inflammation is minimal. Histology of the cyst wall shows no evidence of infective or neoplastic changes, with the MIB labelling index reported to be zero [18]. It is likely that the angiomatous changes and areas of focal thrombosis lead to microhaemorrhages and ischaemic necrosis, which coalesce into cysts or develop into areas of calcification. Loss of blood brain barrier integrity leads to white matter oedema. Inheritance is autosomal recessive, without $\mathrm{X}$ linkage [3, 19]. A germline biallelic mutation in SNORD 118, on chromosome $17 \mathrm{p}$, encoding the small nucleolar RNA U8 (snoRNA U8), has been consistently identified in several cases [3]. There is a large variation in causative mutations, each causing variable loss of function. It is unclear why a ribosomal defect, which would be expected to cause a global disturbance, only leads to specific pathology restricted to the brain. It is likely that LCC occurs in the context of one null mutation and a paired milder mutation; the presence of two null mutations is lethal at the embryonic stage (Ref to Jenkinson 2016).

LCC may present with acute symptoms. The commonest presenting features are pyramidal signs, seizures and a progressive cognitive deficit. The cysts exert mass effect and are directly related to the neurological manifestations of the disease [24]. LCC is restricted to the central nervous system; extra- 


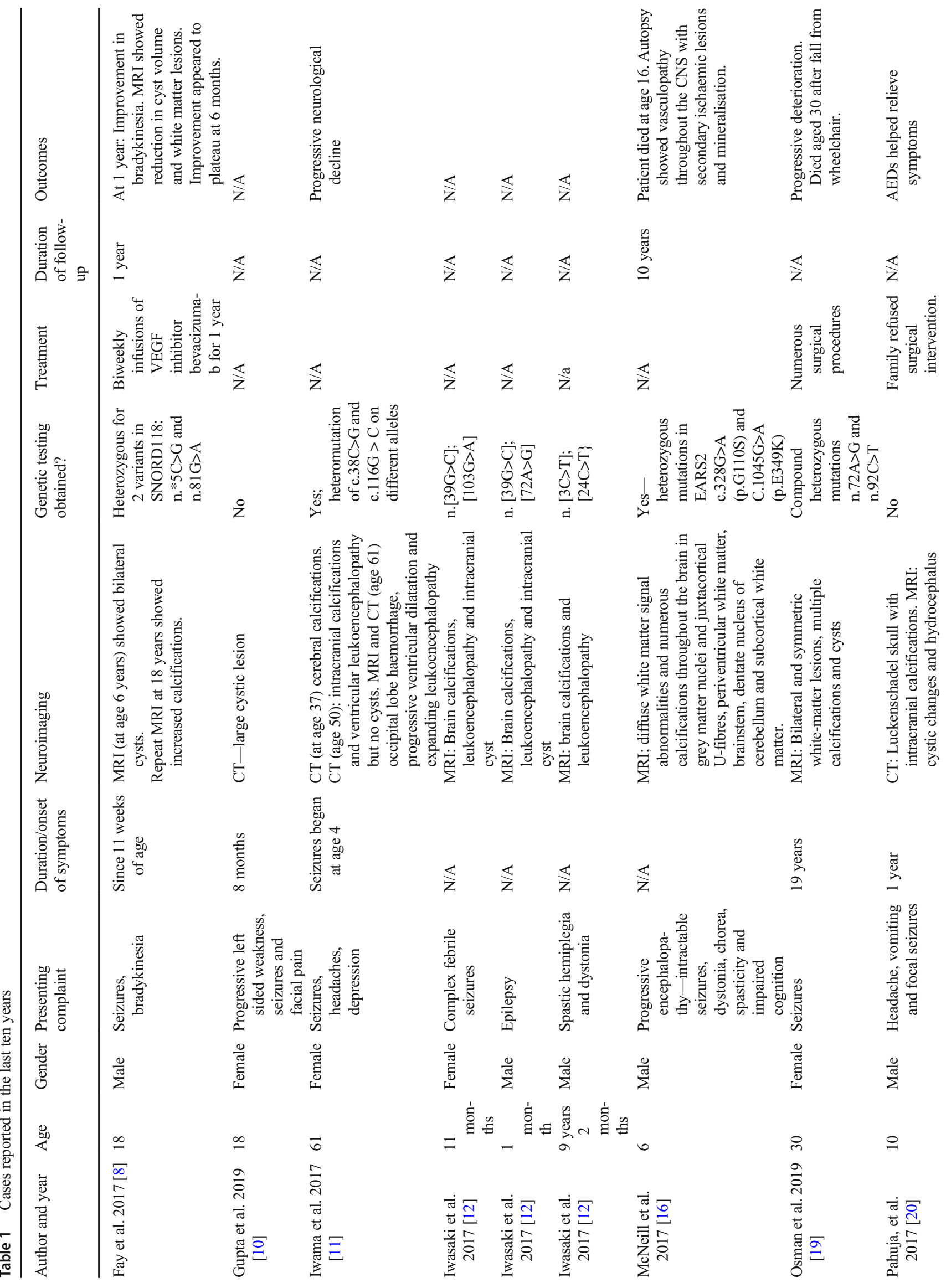




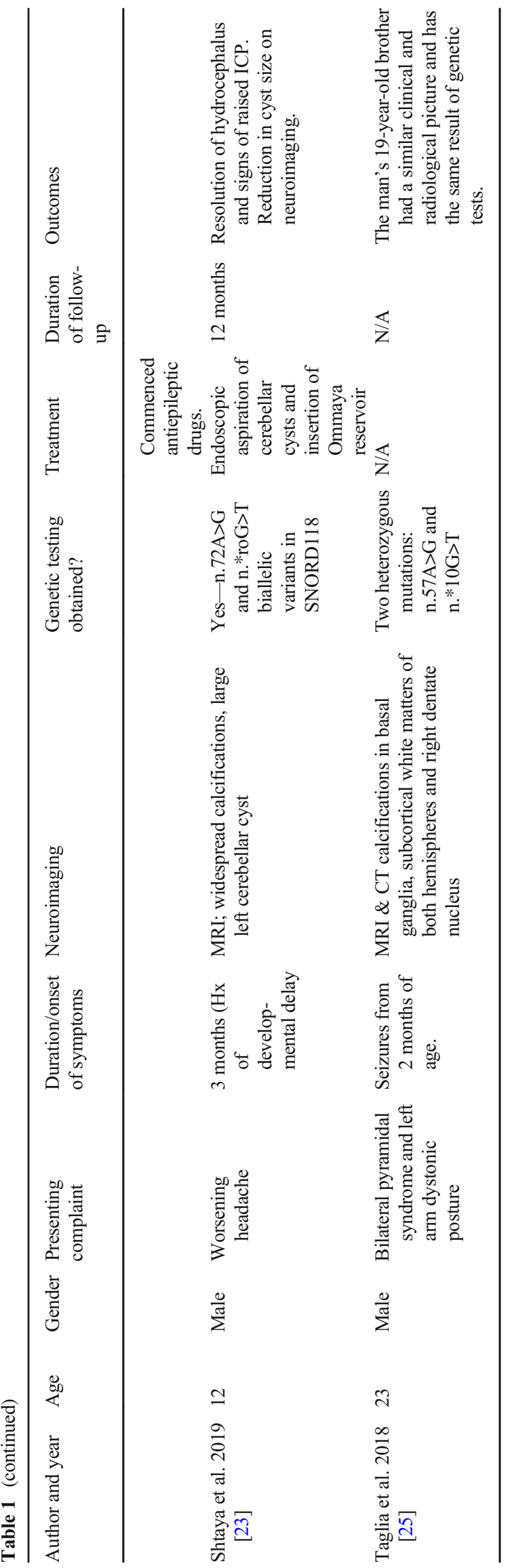

neurologic manifestations have only been described in three patients, with two having café au lait spots and a third demonstrating cysts in the liver, kidney and pancreas $[6,29]$. A related condition, Coats syndrome, is also caused by a microangiopathy; in addition to the cerebral changes, patients with Coats syndrome also have retinal angiopathy, causing bleeding and exudative retinopathy [29]. Coats syndrome is caused by a mutation in the CTC1 gene, located upstream of the SNORD118 gene on chromosome $17 \mathrm{p}$; the mutation affects telomere maintenance and is unrelated to the SNORD 118 mutation in LCC [3]. The Coats Plus syndrome, also related to anomalies in telomere maintenance, has similar neurological manifestations, but is associated with systemic features, including premature greying of hair, anaemia and osteoporosis.

The diagnosis is made primarily on the characteristic triad on radiology. Infections, such as tuberculosis and cytomegalovirus need to be excluded. Fahr disease, Sturge-Weber syndrome and MELAS also demonstrate calcifications, but do not have cysts or leukoencephalopathy [29]. Astrocytoma is an important differential. . However, magnetic resonance spectroscopy (MRS) shows a low choline level in the involved brain, consistent with the high water content in the parenchyma [29]. MRS also shows reduced NAA levels, and no metabolites are evident in cyst fluid. Astrocytomas, by contrast, demonstrate a high choline peak, consistent with rapid membrane turnover. As a biopsy was undertaken in our patient, MRS was not required. Other potential differential diagnoses include Alexander's disease, where cysts and white matter changes are not associated with calcification. In this context, therefore, most cases of LCC can be diagnosed without biopsy or genetic studies.

Few children have been followed up for a long time; in the published paediatric cases we identified, the mean follow-up is 13 months. Natural progression of the disease is not well described. The microangiopathy persists, leading to the development of new cysts or the growth of existing ones within areas of leucoencephalopathy. An adult patient who presented at 44 years and was followed up for 8 years required multiple craniotomies to excise recurring frontal and cerebellar cysts [7]. One patient only received mannitol to control mass effect from the cyst, with subsequent reduction in its size [29]. Many reported cases focus on those who have developed symptoms in adulthood. These symptoms may present suddenly or at a slow, insidious rate. A 69 -year-old woman began to show symptoms at age 37 and demonstrated diffuse bilateral leukoencephalopathy on MRI [6]. A gradual decline in both cognition and motor ability occurred over the next 32 years [6]. In another patient, MRI scans at the age of six showed bilateral cysts in the cerebral hemispheres. It was only at 18 years of age that imaging showed the typical LCC triad, demonstrating the progressive nature of LCC, underlining the importance of long-term follow-up [9]. 
The management of LCC in children is particularly challenging. In some cases, early presentation portends a more aggressive clinical course (Ref Jenkinson 2016). Many of the patients described in Table 1 underwent excision of cysts from the frontal lobe or cerebellum, but as many cysts are located in the thalamus or basal ganglia, this is often not possible without incurring significant neurological deficit. In the context of a progressive neurological disease, that is unpredictable and can also remain stable for a long time, minimally invasive surgical options, such as cyst drainage and insertion of an Ommaya reservoir, are preferable. One study describes the use of biweekly injections of VEGF inhibitor Bevacizumab for one year; this led to a reduction in cyst volume and white matter changes, with a corresponding reduction in bradykinesia, with a plateau at 6 months (ref Fay, 2017).

\section{Conclusion}

Labrune syndrome, also known as LCC, is a rare ribosomopathy with clear diagnostic criteria. Management in children is aimed at reducing mass effect by draining cysts. In the presence of a clear radiological triad, biopsy and genetic studies are not necessary. As the disease process is progressive, long-term follow up is critical. A higher awareness of this rare disease among paediatric neurosurgeons is critical.

Funding Open Access funding provided by the IReL Consortium.

\section{Declarations}

Conflict of interest The authors declare that they have no conflict of interest.

Open Access This article is licensed under a Creative Commons Attribution 4.0 International License, which permits use, sharing, adaptation, distribution and reproduction in any medium or format, as long as you give appropriate credit to the original author(s) and the source, provide a link to the Creative Commons licence, and indicate if changes were made. The images or other third party material in this article are included in the article's Creative Commons licence, unless indicated otherwise in a credit line to the material. If material is not included in the article's Creative Commons licence and your intended use is not permitted by statutory regulation or exceeds the permitted use, you will need to obtain permission directly from the copyright holder. To view a copy of this licence, visit http://creativecommons.org/licenses/by/4.0/.

\section{References}

1. Farley-Barnes K, Ogawa LM, Basergra SJ (2019) Robosompathies: old concepts, new controversies. Trends Genet. 35(10):754-767. https://doi.org/10.1016/j.tig.2019.07.004

2. Labrune $\mathrm{P}$, Lacroix $\mathrm{C}$, Goutières $\mathrm{F}$, de Laveaucoupet $\mathrm{J}$, Chevalier $\mathrm{P}$, Zerah M, Husson B, Landrieu P (1996) Extensive brain calcifications, leukodystrophy and formation of parenchymal cysts: a new progressive disorder due to diffuse cerebral microangiopathy. Neurology. 46(5):1297-1301. https://doi.org/10.1212/wnl.46.5. 1297

3. Jenkinson EM et al (2016) Mutations in SNORD118 cause the cerebral microangopathy leukoencephalopathy with calcification and cysts. Nat Genet. 48(10):1185-1193. https://doi.org/10.1038/ ng.3661

4. Banks GP, Weiss SA, Pisapia D, Willey JZ (2013) A case of lateonset leukoencephalopathy, calcifications, and cysts presenting with intracerebral haemorrhage resembling a neoplasm. Cerebrovasc Dis 35(4):396-397. https://doi.org/10.1159/ 000348312

5. Bertotti MM et al (2011) Leukoencephalopathy, cerebral calcifications, and cysts: entity that can mimic a neoplasm. Arq Neurosiquiatr 69(4):717-722. https://doi.org/10.1590/s0004$282 \times 2011000500027$

6. Bonomo G, Monfrini E, Borellini L, Bonomo R, Arienti F, Saetti MC, Di Fonzo A, Locatelli (2020) Systematic involvement in adultonset leukoencephalopathy with intracranial calcifications and cysts (Labrune syndrome) with a novel mutation of SNORD118 gene. Eur J Neurol. https://doi.org/10.1111/ene.14313

7. Chiang Y, Wang HJ, Chen CY (2019) Adult-onset leukoencephalopathy, cerebral calcifications, and cysts: an 8-year neuroimaging follow-up of disease progression and histopathological correlation. J Clin Neurosci 69:276-279. https://doi.org/10. 1016/j.jocn.2019.08.006

8. Cuillinane PW, Lynch SA, Marnane M (2020) Phenotypic variability in leukoencephalopathy with brain calcifications and cysts: case report of siblings from an Irish traveller family with a homozygous SNORD118 mutation. J Mol Neurosci. https://doi.org/10.1007/ s12031-0200-01550-7

9. Fay AJ, King AA, Shimony JS, Crow YJ, Brunstrom-Nernandez JE (2017) Treatment of leukoencephalopathy with calcifications and cysts with bevacizumab. 71:56-59. https://doi.org/10.1016/j. pediatrineurol.2017.03.008

10. Gulati A, Singh P, Ramanathan S, Khandelwal N (2011) A case of leukoencephalopahy, cerebral calcifications and cysts. Ann Indian Acad Neurol 14(4). https://doi.org/10.4103/0972-2327.91964

11. Gupta MM, Prabhakar A, Joseph L, Garg A, Gaikwad S (2019) Labrune syndrome: a rare cause of reversible hemiparesis. Neurol India. 67(3):934-935

12. Iwama K et al (2017) Identification of novel SNORD118 mutations in seven patients with leukoencephalopathy with brain calcifications and cysts. Clin Genet. 92(2):180187. https://doi.org/10. 1111/cge.12991

13. Iwasaki Y, Hoshino KI, Mori K, Ito M, Kawai Y, Mimuro M, Tsukie T, Ikeuchi T, Yoshida M (2017) Longitudinal clinical and neuro-radiological findings in a patient with leukoencephalopathy with brain calcifications and cysts (Labrune syndrome). eNeurologicalSci. 8:28-30. https://doi.org/10.1016/j.ensci.2017. 07.003

14. Li Z, Han K, Yao W, Wei W, Li U, Lan X (2015) Adult onset leukoencephalopathy with calcifications and cysts: focusing on hemorrhagic propensity and cysts development. World Neurosurg 85:366. https://doi.org/10.1016/j.wneu.2015.09.049

15. Liu X, Zheng X, Sui Q, Xu W, Zee C (2016) Leukoencephalopathy with cerebral calcifications and cysts: clinical and pathological features in two adults. Acta Neurol Belg 116. https://doi.org/10.1007/ s137600-015-0501-5

16. Ma Y, Zhang X, Cheng C, Xu Q, Di H, Zhao J, Huang D, Yu S (2017) Leukoencephalopathy with calcifications and cysts: a case report. Medicine (Baltimore) 96(29):e7597. https://doi.org/10. 1097/MD.0000000000007597

17. McNeill N, Nasca A, Reyes A, Lemoine B, Cantarel B, Vanderver A, Chiffmann R, Ghezzi D (2017) Functionally pathogenic EARS2 
variants in vitro may not manifest a phenotype in vivo. Neurol Genet 14:3 (4). https://doi.org/10.1212/NXG.0000000000000162

18. Novo J, Lin D, Shanks M, Kocak M, Arvanitis L (2017) A 55-yearold female with leukoencephalopathy with cerebral calcifications and cysts: case report and radiopathologic description. Pathol Res Pract 213(11):1440-1444. https://doi.org/10.1016/j.prp.2017.07. 007

19. Ogles RL, Joshi CL, Miller DC, Litofsky NS, Travis MD (2014) Leukoencephalopathy, cerebral calcifications and cysts in two sisters. Pediatr Neuro 51(4). https://doi.org/10.1016/j.pediatrneurol. 2014.06.007

20. Osman O, Labrune P, Reiner P, Sarov M, Nasser G, Riant F, Tournier-Lasserve E, Chabriat H, Denier C (2019) Leukoencephalopathy with calcifications and cysts (LCC): 5 cases and literature review. Rev Neurol (Paris). https://doi.org/10.1016/j. neurol.2019.06.006

21. Pahuja L, Patras E, Sureshbabu S, Parkhe N, Khanna L (2017) Labrune syndrome: a unique leukoencephalopathy. Ann Indian Acad Neurol 20(1):59-61. https://doi.org/10.4103/0972-2327. 192386

22. Pessoa A (2018) Blood-brain barrier permeability in a patient with Labrune syndrome due to SNORD118 mutations: would this be the mechanism for progressive worsening? Eur J Neurol. 25(8). https:// doi.org/10.1111/ene.13671

23. Pessoa A, Monteiro Ado V, Queiroz RF, Malveira GL, Kok F (2012) Leukoencephalopathy with cerebral calcifications and cyst: Labrune syndrome. Arq Neuropsiquiatr. 70(3). https://doi.org/10. 1590/s0004-282x2012000300016

24. Shtaya A, Elmslie F, Crow Y, Hettige S (2019) Leukoencephalopahy, intracranial calcifications, cysts and SNORD118 mutation (Labrune syndrome) with obstructive hydrocephalus. World Neurosurg. 125:271-272. https://doi.org/ 10.1016/j.wneu.2019.02.008

25. Stephani C, Pfeifenbring S, Mohr A, Stadelmann C (2016) Lateonset leukoenceopahlopathy with cerebral calcifications and cysts: case report and review of the literature. BMC Neurol 16:19. https:// doi.org/10.1186/s12883-016-0543-1

26. Taglia I, Do Donato I, De Stefano N, Bianchi S, Galluzzi P, Federico A, Dotti MT (2018) Blood-brain barrier permeability in a patient with Labrune syndrome due to SNORD118 mutations. Eur J Neurol. https://doi.org/10.1111/ene.13656

27. Tamura R, Ohira T, Emoto K, Fujiwara H, Horikoshi T, Yoshida K (2017) Leukoencephalopathy, cerebral calcifications, and cysts: a clinical case involving a long term follow-up and literature review. 373:60-85. https://doi.org/10.1016/j.jns.2016.12.014

28. Ummer K, Salam KA, Noone ML, Kumar VG, Mampillu N, Sivakumar S (2010) Leukoencephalopathy with intracranial calcifications and cysts in an adult: case report and review of the literature. Ann Indian Acad Neurol 13(4). https://oi.org/10.4103/ 0972-2327.74198

29. Wang M, Zhang M, Wu L, Dong Z, Yu S (2016) Leukoencephalopathy with cerebral calcification and cysts: case report and literature review. J Neurol Sci 370:173-170. https://doi. org/10.1016/j.jns.2016.09.048

30. Wang Y, Cheng G, Dong C, Zhang J, Leng Y (2013) Adult-onset leukoencephalopathy, brain calcifications and cysts: a case report. J Med Case Rep 7:151. https://doi.org/10.1186/1752-1947-7-151

Publisher's note Springer Nature remains neutral with regard to jurisdictional claims in published maps and institutional affiliations. 